\title{
Multidimensional Traffic Locus of Control and Driving Skills as Predictors of Quality of Life among Drivers
}

\author{
Rajesh Kumar ${ }^{1 *}$, Beenu Varma ${ }^{2}$ \\ ${ }^{1}$ Associate Professor, Dept of Psychology, PG Govt. College, Sector 46, Chandigarh India \\ ${ }^{2}$ Assistant Professor, Dept of Psychology, PG Govt. College, Sector 46, Chandigarh India
}

\begin{tabular}{|c|c|}
\hline $\begin{array}{c}\text { Article History } \\
\text { Received: } 12.08 .2020 \\
\text { Accepted: } 03.09 .2020 \\
\text { Published: } 10.10 .2020 \\
\text { Journal homepage: } \\
\text { https://www.easpublisher.com/easjpbs } \\
\text { Quick Response Code }\end{array}$ & $\begin{array}{l}\text { Abstract: The purpose of the present investigation was to study the quality of life with } \\
\text { driving skills and traffic locus of control among drivers. For this purpose quality of life } \\
\text { developed by Vandana Kaushik and Purva Jaggi, (2008), Multidimensional Traffic } \\
\text { Locus of Control (T-LOC, Ozkan \& Lajunen, 2005) and Driver Skill Inventory (DSI } \\
\text { Driver skill inventory developed by Lajunen \& Summala in 1995) were administered on } \\
\text { the sample selected from the tricity. The total sample consists of } 900 \text { young adult drivers. } \\
\text { Descriptive statistics, correlation and multiple regression analysis were used as statistical } \\
\text { analysis. Results revealed that quality of life was positively related with perceptual motor } \\
\text { skills }(\mathrm{r}=.492) \text {, safety skills }(\mathrm{r}=.643) \text {, TLOC self }(\mathrm{r}=.434) \text {, TLOC VE }(\mathrm{r}=.191 \text { ) and } \\
\text { TLOC other drivers }(\mathrm{r}=.182) \text {. It was also concluded that safety skills, TLOC self and } \\
\text { TLOC VE were emerged as good predictors (multiple R square }=43.5 \%) \text { of the quality }\end{array}$ \\
\hline
\end{tabular}

Keywords: Traffic congestion, quality of life, traffic locus of control, driving skills.

\begin{abstract}
Copyright (C) 2020 The Author(s): This is an open-access article distributed under the terms of the Creative Commons Attribution license which permits unrestricted use, distribution, and reproduction in any medium for non-commercial use (Non Commercial, or CC-BY-NC) provided the original author and source are credited.
\end{abstract}

\section{INTRODUCTION}

Various researches have been done to know the behavior, cognition, control, perception, skills, knowledge of the driver, and understanding between drivers while driving. Driving appears a simple task but it involves too many tasks simultaneously as it requires attention at a particular time on various things. In traffic jam drivers lose their patience and start using abusive and bad language. Traffic congestion makes the drivers aggressive [1]. They attempted that frustration aggression theory describes that traffic jam are goal blocking and it interferes driving progress. Overcrowding of vehicles and people leads to chaos in parking as well as on roads respectively. All these things deteriorate the quality of life of the drivers. According to Ding, Gebel, phongsavan, Bauman and Merom [2] daily driving was associated with increase in the weight, psychological distress, social dysfunctioning, reduction in the health and quality of life of the drivers. For better quality of life what person need is the satisfaction derives from his/her own materialistic things. As per the other researchers like Kageyama, Nishikido, Kobayashi, Kurokawa, Kaneko, et al. [3] and Rasmussen, Knapp and Garner [4] during long driving hours and traffic congestion driver's compromises with their health includes stress and anxiety. During traffic congestion the person stuck at a point where he is not able to move his vehicle and due to this the allotted assignments remain pending and the person gets irritated, frustrated and depressed. Driving skills can help the drivers to get out of the traffic jam and can drive smoothly. According to Elander, West and French [5], driving skills refer to how good a person is at handling the vehicle. Environmental conditions and climate, road conditions, rat runners, passengers and speed of the other vehicles affect the driving skills. The one who faces such challenges and react patiently leads to resolve the problems otherwise it leads to chaos, congestion, accidents, harms, misbehave, aggression and frustrations which further affects the mental health and quality of life of the drivers. Arain, Shaikh and Shaikh [6] conducted a study on traffic congestion and driving behavior and found that different driving behavior of drivers are inter dependent while they drive. The result depicts the significant relationship between drivers' behavior. Authors suggested the methods to remove traffic jam by implementation of traffic rules and manage unlawful driving behavior. Researchers also concluded that the implementations of the traffic rules and use of driving skills increases the quality of life and excellence of the drivers. Neelima, Gupta, Pathi and Riku [7] found that inappropriate driving behaviour is considered to be one of the major causes of road crashes in India as compared to defective designs of roads. It was found 
that $65 \%$ of road accidents on Indian roads are caused due to the fault of the road users apart from the other factors like poor road condition and bad weather etc.

Another variable which is taken into consideration is the traffic locus of control which includes the locus of control self, locus of control fate, locus of control vehicle and environment and locus of control other drivers. Rotter [8] defined locus of control as "a personality attribute reflecting the degree to which a person generally perceive events to be under their own control (internal locus of control) or under the control of powerful others or other outside forces (external locus of control)". In road safety rules locus of control plays an important role because locus of control is the kind of obedience or agreement with the self or with others. It is a kind of personality trait to which person believes. On road some persons believe that the safety and security events to be under their own control. Some drivers believe all under the control of powerful others or other outside forces (E-LOC) while some believes on the luck or fate.

To eradicate traffic congestion or to control the jams on roads which affect the quality of life, leads to psychological problems internal locus of control is needed. In internal locus of control we do not require the traffic police or the ones who maintain the law and order on roads. There is a relationship between locus of control and driving behavior. Researchers found that changes in driving locus of control predicted an increase in safe driving behavior. Drivers with internal locus of control are more toward safe driving behavior and drivers who report external locus of control are low on safety measures and driving skills [9]. Arthur and Doverspike [10] found that the relation between T-LOC and driving behaviour was not clear and the evidence on the association of both was mixed. Alper and Ozkan [11] opined that there was positive association between external traffic locus of control and risk perception and a negative association between external traffic locus of control and risky driving behavior.

Thus from the above conceptual framework and literature available the objectives of the present study were (a) To study the relationship between quality of life and driving skills among young adult drivers. (b) To study the relationship between quality of life and traffic locus of control among young adult drivers. (c) To study the role of driving skills and traffic locus of control in determining the quality of life among young adult drivers.

\section{The literature review suggests the following hypotheses}

Hypothesis 1: Quality of life, perceptual motor skills and safety skills are positively related with each other among young adult drivers.
Hypothesis 2: Quality of life, TLOC self, TLOC VE and TLOC other drivers are positively related with each other among young adult drivers.

Hypothesis 3: Quality of life and TLOC fate are negatively related with each other among young adult drivers.

Hypothesis 4: Multidimensional traffic locus of control (self, fate, vehicle and environment and other drivers) and driving skills (perceptual motor skills and safety skills) plays an important role in determining quality of life among young adult drivers.

\section{Material and Methods Participants and Procedure}

The present research aims to study the mushrooming traffic on roads which leads to congestion and its psychological implications among drivers. The sample for the study is comprised of 900 young adults ranging in the age of 25 to 40 years and was selected randomly from tricity i.e. Chandigarh, Panchkula and Mohali.

\section{Inclusion Criteria}

- Only those drivers were included who are having valid driving license.

- Drivers having experience of driving of last five years were included in the present study.

\section{Exclusion Criteria}

- Drivers having any psychological or physiological problems were excluded from the present study.

- Drivers having experience of less than five years of driving were also excluded.

- Drivers having any substance or drug abuse were not included in the research.

After developing a good rapport, consent was taken from the subjects and the purpose of study was shared. After having structured interview instructions were provided to the subjects and standardized tools were administered. The participants were assured of having anonymity and confidentiality. The administration of tools was followed by a brief interview with every driver.

\section{Measurements}

1. Quality of Life Vandana Kaushik and Purva Jaggi, 2008

2. Multidimensional Traffic Locus of Control TLOC, Ozkan and Lajunen, 2005

3. Driver Skill Inventory (DSI Driver skill inventory developed by Lajunen and Summala in 1995 


\section{Statistical Analysis} the results.

Descriptive statistics, correlation and multiple regression was used with the help of SPSS version 25 to analyze

\section{RESULTS AND DisCUSSION}

Table-1: Mean and Standard Deviation of the measured variables among drivers

\begin{tabular}{|r|l|l|l|}
\hline S. No & Variables & Mean & SD \\
\hline 1. & Quality of Life & 69.50 & 12.47 \\
\hline 2. & TLOC Self & 16.04 & 4.15 \\
\hline 3. & TLOC Fate & 7.03 & 2.03 \\
\hline 4. & TLOC Vehicle and Environment & 8.91 & 2.09 \\
\hline 5. & TLOC Other Divers & 17.06 & 5.77 \\
\hline 6. & Perceptual Motor Skills & 14.61 & 4.34 \\
\hline 7. & Safety Skills & 61.66 & 17.92 \\
\hline
\end{tabular}

A perusal of Table 1 shows the mean and SD of each variable in the data set. Drivers have mean quality of life as 69.50 and SD as 12.47 . Mean \pm SD was found to be $16.04 \pm 4.15$ for traffic locus of control self, $7.03 \pm 2.03$ for traffic locus of control fate, 8.91 \pm 2.09 for traffic locus of control vehicle and environment, $17.06 \pm 5.77$ for traffic locus of control other drivers, $14.61 \pm 4.34$ for perceptual motor skills and $61.66 \pm 17.92$ for safety skills.

Table-2: Correlation Matrix of the measured variables among drivers

\begin{tabular}{|l|l|l|l|l|l|l|c|}
\hline Variables & QOL & TLOC Self & TLOC Fate & TLOC VE & TLOC OD & PMS & SS \\
\hline QOL & 1 & $.434^{* *}$ & -.003 & $.191^{* *}$ & $.182^{* *}$ & $.492^{* *}$ & $.643^{* *}$ \\
\hline TLOC Self & & 1 & $.072^{*}$ & $.302^{* *}$ & $.134 * *$ & $.384^{* *}$ & $.490^{* *}$ \\
\hline TLOC Fate & & & 1 & .027 & -.001 & $-.069^{*}$ & $-.077^{*}$ \\
\hline TLOC VE & & & & 1 & .011 & $.140^{* *}$ & $.169^{* *}$ \\
\hline TLOC OD & & & & & 1 & $.279 * *$ & $.224 * *$ \\
\hline PMS & & & & & & 1 & $.704 * *$ \\
\hline SS & & & & & & & 1 \\
\hline
\end{tabular}

Table 2 shows the pearson's correlation coefficient between quality of life and traffic locus of control (self, fate and vehicle and environment and other drivers and between quality of life and driving skills (perceptual motor skills and safety skills). The quality of life was found to be positively and significantly with TLOC self $(\mathrm{r}=.434, \mathrm{p}<0.01)$, TLOC VE $(r=.191, p<0.01)$, TLOC OD $(r=.182, p<0.01)$. Quality of life was negatively and insignificantly related with TLOC fate $(r=-.003, p>0.05)$. Quality of life found to be positively and significantly related with perceptual motor skills $(\mathrm{r}=.492, \mathrm{p}<0.01)$ and with safety skills $(\mathrm{r}=.643, \mathrm{p}<0.01)$.

\section{Thus hypotheses no. 1, 2 and 3 were upheld in all the} cases.

With traffic locus of control (self) quality of life was positively associated which implies that satisfaction with life and wellbeing increases as the selflocus of control increases or vice versa [9]. Life will be free from external conflicts as TLOC self-determines the causes of accidents, congestion on road attributed to one self. If the drivers' feels like causes of accidents may be due to lack of my knowledge, lack of concentration while driving, shortcomings in my driving etc. then the driver can improve his driving and it can lead to healthy feeling towards internally and no conflicts with other drivers too. It may be implied to some drivers not all the drivers on road. Because many of the drivers blame others too and this may be the reason that quality of life was positively related with TLOC other drivers and TLOC vehicle and environment. Other reason of this positive relationship could be no guilt of feelings toward self, charge the environmental conditions like bad weather, construction on road etc and simultaneously hold responsible the other commuters and drivers for the mishappening, road rage and congestion on road. Self-locus of control drivers were more responsible, having internal attribution, regular use of seat belt while driving, use of helmets while riding as compare to those who were towards LOC other drivers and LOC vehicle and environment.

TLOC fate and quality of life found to be negatively and insignificantly related with each other. Drivers who believed in fate, luck, chance, coincidence, fortune etc were low on quality on life because they do not believe in the style of driving, skills, learning etc.

For the quality of life and driving skills the value of $\mathrm{r}$ depicts affirmative and significant results. 
Higher the perceptual motor skills and safety skills higher will be the quality of life. Drivers having skills how to drive safely and comfortably and simultaneously not over confident were high on quality of life. Controlling the vehicle, driving fast if necessary, driving in strange city, overtaking at correct moment and knowing how to act in particular situations lead the driver's life healthy and happy [5]. Too much congestion on road and do not know how to get rid off from this congestion makes the drivers feel more anxious and stressful which directly or indirectly affect their personal life too.

Table-3: Model summary of multiple stepwise regression analysis for variables safety skills, TLOC self, TLOC VE as predictor and the quality of life as criterion variable

\begin{tabular}{|c|c|c|c|c|c|c|c|c|c|}
\hline Model & $\mathbf{R}$ & $\begin{array}{l}\text { Multiple R } \\
\text { Square }\end{array}$ & $\begin{array}{l}\text { Adjusted R } \\
\text { Square }\end{array}$ & $\mathbf{F}$ & df & $\mathbf{P}$ & $\begin{array}{l}\text { R Square } \\
\text { Change }\end{array}$ & $\begin{array}{l}\mathbf{F} \\
\text { Change }\end{array}$ & $\mathbf{P}$ \\
\hline 1 & $.643^{\mathrm{a}}$ & .414 & .413 & 634.37 & 1,898 & .000 & .414 & 634.37 & .000 \\
\hline 2 & $.658^{b}$ & .433 & .431 & 342.17 & 2,897 & .000 & .019 & 29.69 & .000 \\
\hline 3 & $.660^{\mathrm{c}}$ & .435 & .433 & 230.22 & 3,896 & .000 & .003 & 4.01 & .045 \\
\hline \multicolumn{10}{|c|}{ a. Predictors: (Constant), DSI Safety Skill } \\
\hline \multicolumn{10}{|c|}{ b. Predictors: (Constant), DSI Safety Skill, TLOC Self } \\
\hline \multicolumn{10}{|c|}{ c. Predictors: (Constant), DSI Safety Skill, TLOC Self, TLOC VE } \\
\hline \multicolumn{10}{|c|}{ Dependent Variable: Quality of Life } \\
\hline
\end{tabular}

Only three variables viz., safety skills, TLOC self and TLOC VE were found as predictors of quality of life as per the analysis done in SPSS version 25 . In Table 3 model 1 refers to the first stage in the hierarchy when only safety skills were used as predictor. The value of $\mathrm{R}$ was found to be 0.643 which depicts the correlational value between the predictor and the criterion variable. Multiple $\mathrm{R}$ square was .414 which means that only safety skills among drivers account $41.4 \%$ of the variation in the quality of life. It was found to be a good and significant predictor as the $\mathrm{F}$ value was 634.37, $\mathrm{p}<0.01$. Other predictors TLOC self and TLOC VE account .019 and .003 in the criterion variable. The second predictor was found to be significant at 0.01 and the last predictor TLOC VE was significant at 0.05 .

Finally the multiple R square was comes out to be .435 which clearly disclosed that all the three predictors contribute $43.5 \%$ (multiple $\mathrm{R}$ square $=.435$, $\mathrm{p}<0.05$ ) variation in the criterion variable quality of life. Driving safety skills as predictor has explained quite a large amount of the variation in quality of life. 0.433 value of adjusted $\mathrm{R}$ square gives idea how well the model generalizes and ideally its value to be the very close to the value of multiple $\mathrm{R}$ square which was .435 . This shrinkage means that if the model were derived from the population rather than sample it would account for $0.2 \%$ less variance in the outcome.

Table-4: Regression coefficients of the variables safety skills, TLOC self and TLOC VE as predictor

\begin{tabular}{|l|c|c|c|c|c|}
\hline \multirow{2}{*}{ Variables } & Unstandardized $\beta$ Coefficients & Standardized $\boldsymbol{\beta}$ Coefficients & $\mathbf{t}$ & $\mathbf{p}$ \\
\cline { 2 - 3 } & $\boldsymbol{\beta}$ & Std. Error & & & \\
\hline Safety Skills & .393 & .020 & .565 & 19.61 & .000 \\
\hline TLOC Self & .426 & .089 & .142 & 4.76 & .000 \\
\hline TLOC VE & .314 & .157 & .053 & 2.00 & .045 \\
\hline
\end{tabular}

The above table shows the model parameters. The $\beta$ value found to be .393 which depicts the positive association between safety skills and quality of life as this value was positive in nature. This value also indicates that as the safety skills changes by one value quality of life changes in the same direction with .393 values. Further from the value of $t(t=19.61, p<0.01)$ it was concluded that safety skills makes a significant contribution in predicting quality of life. Similarly TLOC self and TLOC VE also found to be a significant predictors of quality of life. The beta value found to be .426 and .314 for the TLOC self $(\mathrm{t}=4.76, \mathrm{p}<0.01)$ and TLOC VE $(\mathrm{t}=2.00, \mathrm{p}<0.05)$ respectively. All these predictors directly predict quality of life among drivers and emerged as good predictors.

\section{CONCLUSION AND IMPLICATIONS}

It was concluded that quality of life was positively and significantly associated with safety skills and perceptual motor skills. It was also opined that quality of life was positively and significantly related with traffic locus of control self, vehicle and environment and other drivers.

It was also finale that safety skills, TLOC self and TLOC VE were emerged as predictor of the quality of life among young adult drivers. The present investigation will be very helpful for the drivers especially because locus of control basically work out for the subjects only. Internal locus of control need to be enhance it will automatically raises the curiosity to learn more skills of the driving and reduces the chances of road rage, impatience among drivers. Further the 
quality of life of the drivers will be better if they are high on skills to handle the vehicle in congestion, bad weather and during construction on road.

Govt. can make policies for the truck drivers and transporters like on regular basis driving awareness programme should be inculcated among the young drivers with the help of audio video resources. Reducing congestion in a growing metropolitan area will be typically achieved by implementing a combination of strategies that maximize available capacity, reduce automobile use, and reduce the growth in motor vehicle traffic. These strategies might involve increasing the choice in the number of routes and travel modes, or the creating traffic lanes that involve the payment of a toll for higher speed and higher travel time reliability.

\section{REFERENCES}

1. Mina, S., Verma, R., Balhara, Y. P. S., \& U1Hasan, S. (2014). Road rage: Prevalence pattern and Web based survey feasibility. Psychiatry Journal, 1-7.

2. Ding D, Gebel, K., Phongsavan, P., Bauman, A. E., \& Merom, D. (2014). Driving: A road to unhealthy lifestyles and poor health outcomes. Plos One 9 (6).

3. Kageyama, T., Nishikido, N., Kobayashi, T., Kurokawa, Y., Kaneko, T. (1998). Long commuting time, extensive overtime, and sympathodominant state assessed in terms of shortterm heart rate variability among male white-collar workers in the Tokyo megalopolis. Industrial Health 36(3), 209-217.
4. Rasmussen, C., Knapp, T. J., \& Garner, L. (2000). Driving-induced stress in urban college students. Perceptual Motor Skills 90(2), 437-443.

5. Elander, J., West, R., \& French, D. (1993). Behavioral correlates of individual differences in road-traffic crash risk: An examination of methods and findings. Psychological Bulletin, 113(2), 279294.

6. Arain, S., Shaikh, F., \& Shaikh, M. M. (2017). Problem of Traffic Congestion and correlation analysis of Driving behaviors in Qasimabad, Hyderabad. Research Journal of Engineering \& Technology, 36(1), 139-148.

7. Neelima, C., Gupta, K., Senthipathi, V., \& Riku, R. (2015). Assessment of Driving Behaviour and Skills of Heavy Vehicle Drivers in India. Paper ID. 451.

8. Rotter, J. B. (1966). Generalized expectancies for internal versus external control of reinforcement. Psychological Monographs, 80(1), 1.

9. Huang, J. L., \& Ford, J. K. (2012). Driving locus of control and driving behavior: Including change through driver training. Transportation Research Part F: Traffic Psychology and Behavior, 15, 358368.

10. Arthur, W., \& Doverspike, D. (1992). Locus of control and auditory selective attention as predictors of driving accident involvement: A comparative longitudinal investigation. Journal of Safety Research, 23, 73-80.

11. Alper, S., \& Özkan, T. (2015). Do internals speed less and externals speed more to cope with the death anxiety?. Transportation Research Part F: Traffic Psychology and Behaviour, 32, 68-77. 